\title{
Analysis of outcome of percutaneous versus open pedicle screw fixation in the treatment of thoraco-lumbar spine fractures: a prospective comparative study
}

\author{
Raj Kumar', Bhaskar Sarkar ${ }^{1 *}$, Syed Ifthekar $^{2}$, Samarth Mittal $^{2}$, \\ Pankaj Kandwal'2, Quamar Azam ${ }^{1}$
}

\begin{abstract}
${ }^{1}$ Department of Orthopedics, Trauma Surgery and ${ }^{2}$ Spine Surgery, All India Institute of Medical Sciences, Rishikesh, Uttarakhand, India
\end{abstract}

Received: 18 December 2020

Accepted: 18 January 2021

*Correspondence:

Dr. Bhaskar Sarkar,

E-mail: drbhaskarsarkar@gmail.com

Copyright: () the author(s), publisher and licensee Medip Academy. This is an open-access article distributed under the terms of the Creative Commons Attribution Non-Commercial License, which permits unrestricted non-commercial use, distribution, and reproduction in any medium, provided the original work is properly cited.

\begin{abstract}
Background: Aim of the study was to evaluate the effectiveness between percutaneous and open pedicle screw fixation in the treatment of traumatic thoracolumbar burst fractures with spinal injury.

Methods: A prospective comparative study including thirty patients with thoracolumbar burst fracture were equally divided into an open pedicle screw fixation (OPSF) group and a percutaneous pedicle screw fixation (PPSF) group. Demographic characteristics, clinical and radiological outcomes, and adverse events were assessed and compared between the 2 groups.

Results: Demographic and clinical features including age, gender, fracture level, mechanism of injury and neurological status in both groups were not significantly different (all p>0.05). The PPSF group exhibits significantly lower operative time, intraoperative blood loss, and hospital stay compared with the OPSF group (all $\mathrm{p}<0.05)$. There was no significant difference in the sagittal Cobb's angle (CA), fracture vertebral body angle (VBA), anterior vertebral body height $(\mathrm{AVBH})$ on pre-operative, immediate post-operative and final follow up between the two surgical techniques (all $\mathrm{p}>0.05$ ). Visual analogue scale (VAS) remarkably decreased in both groups after surgery but difference was not statically significant $(\mathrm{p}=0.808)$. Common postoperative complications in both groups were superficial infections, pressure ulcer and urinary tract infection (UTI) worsening. Hardware failure was seen only in one case of PPSF group. Conclusions: Patients with thoracolumbar burst fractures can be effectively managed with PPSF/OPSF. There were no significant differences in radiological and clinical outcomes and post-op complications between 2 groups but blood loss, operative time and hospitalization stay were less in percutaneous group, which may represent a potential benefit.
\end{abstract}

Keywords: Thoraco-lumbar burst fracture, OPSF, PPSF, Prospective comparative study

\section{INTRODUCTION}

Fractures of the thoracic and lumbar vertebrae are quite common injuries among polytrauma patients, and nearly one-third of those patients have concomitant neural structure injury and variable neurologic deficit. ${ }^{1}$ Almost $60 \%$ of spinal fractures occur within the thoracolumbar region, with $17 \%$ being burst fracture. ${ }^{2,3}$ These injuries are painful and may impact quality of life resulting in prolong absence from work and chronic pain; thus, having significant socio-economic impact furthermore. ${ }^{4}$

These injuries are usually resulting of high energy trauma like motorized vehicle accidents or falls from height and more common in men. Elderly people also are in danger for these fractures, because of weakened bone from osteoporosis. $^{5}$ 
The primary goals of treatment for such fractures include protecting the neural elements and preventing deformity and instability. The treatment depends on the individual characteristics of the fracture that range from compression fractures and burst fractures to flexion distraction injuries with fracture dislocation, which may be managed conservatively including bed rest alone, closed reduction of fractures and functional bracing, and surgical managements involving open reduction and internal fixation of the fracture. However, studies have advocated that nonoperative treatments were related to late neurologic decline in 10 to $20 \%$ of patients and were fraught with its difficulty in moving., ${ }^{4,6}$ Pedicle screw fixation has been widely applied in clinical practice to produce stable spinal fixation, which exerts few negative influence on the nervous system, blood vessels, and internal organs of the patients. ${ }^{7}$ Despite that the utilization of a standard open pedicle screw fixation (OPSF) and reduction of thoracolumbar fractures has demonstrated good radiologic and clinical outcomes, several potential disadvantages can occur from OPSF, including trauma to soft tissue, blood loss, long duration of hospital stay, high risk of postoperative complications, which can increase the suffering and economic burden of the patients especially in low-income families. ${ }^{8,9}$ Thus, a replacement perspective within the treatment of thoracolumbar fractures was offered with the event of percutaneous pedicle screws fixation (PPSF) procedure, which performed by sparing the paravertebral musculature and avoiding damage to the zygapophysial joint, may also reduce bleeding, postoperative pain, operative time, and also the length of hospitalization, which make rehabilitation easier and faster. ${ }^{10,11}$ Further, image navigation systems can facilitate insertion of pedicle screw and minimize misplacement. ${ }^{12}$

However, critical and substantial evaluation of percutaneous pedicle screw fixation procedures in thoracolumbar fracture is scant, and no study to our knowledge has analyzed the use of percutaneous techniques in traumatic thoracolumbar fractures compared with open techniques in our institution. Therefore, we aimed to compare the clinical and radiological outcomes of using PPSF and OPSF to treat thoracolumbar fractures.

\section{METHODS}

This prospective comparative study was conducted at a tertiary care center in Uttarakhand, India over a period of two years four months from December 2017 to March 2020. Total 30 patients meeting the inclusion criteria were studied. Patients were randomly subjected to PPSF (Figure 1) or OPSF (Figure 2) surgery, and including 15 patients in each group. Inclusion criteria included skeletally mature patients (more than 18 years) with no age restriction, no gender restriction, presence of a thoracolumbar fracture (T10-L5) with TLICS score of $\geq 4$, surgical management, and follow up of a minimum of 1 year. ${ }^{13}$ Patients with history of trauma more than 5 days, multilevel spinal injury, multi-organ trauma, pathologic or osteoporotic fractures, poor anesthetic patients, pregnant patient, and patients not willing to participate were excluded from study. Study was approved by institutional ethics committee and written informed consent was obtained from all patients before surgical procedure and for participation in the study.

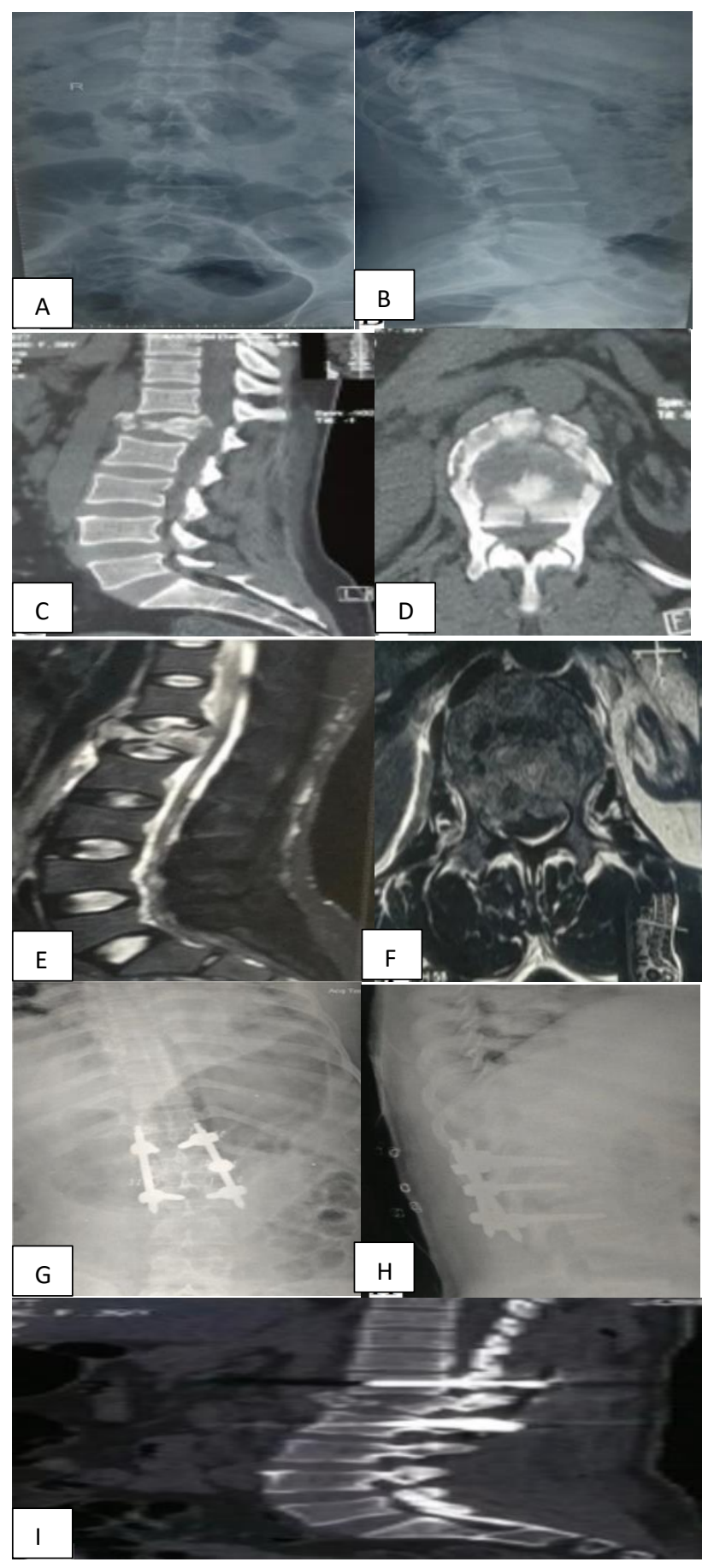

Figure 1: Radiological films of 39-year-old female with L1 burst fracture caused by fall from height and treated with PPSF. Pre-operative- (A and B) Anteroposterior and lateral radiograph; (C and D) CT scan: sagittal and axial view; ( $\mathrm{E}$ and F) MRI film: sagittal and axial view. Post-operative- (G and H) Anteroposterior and lateral radiograph; (I) CT scan: sagittal view. 

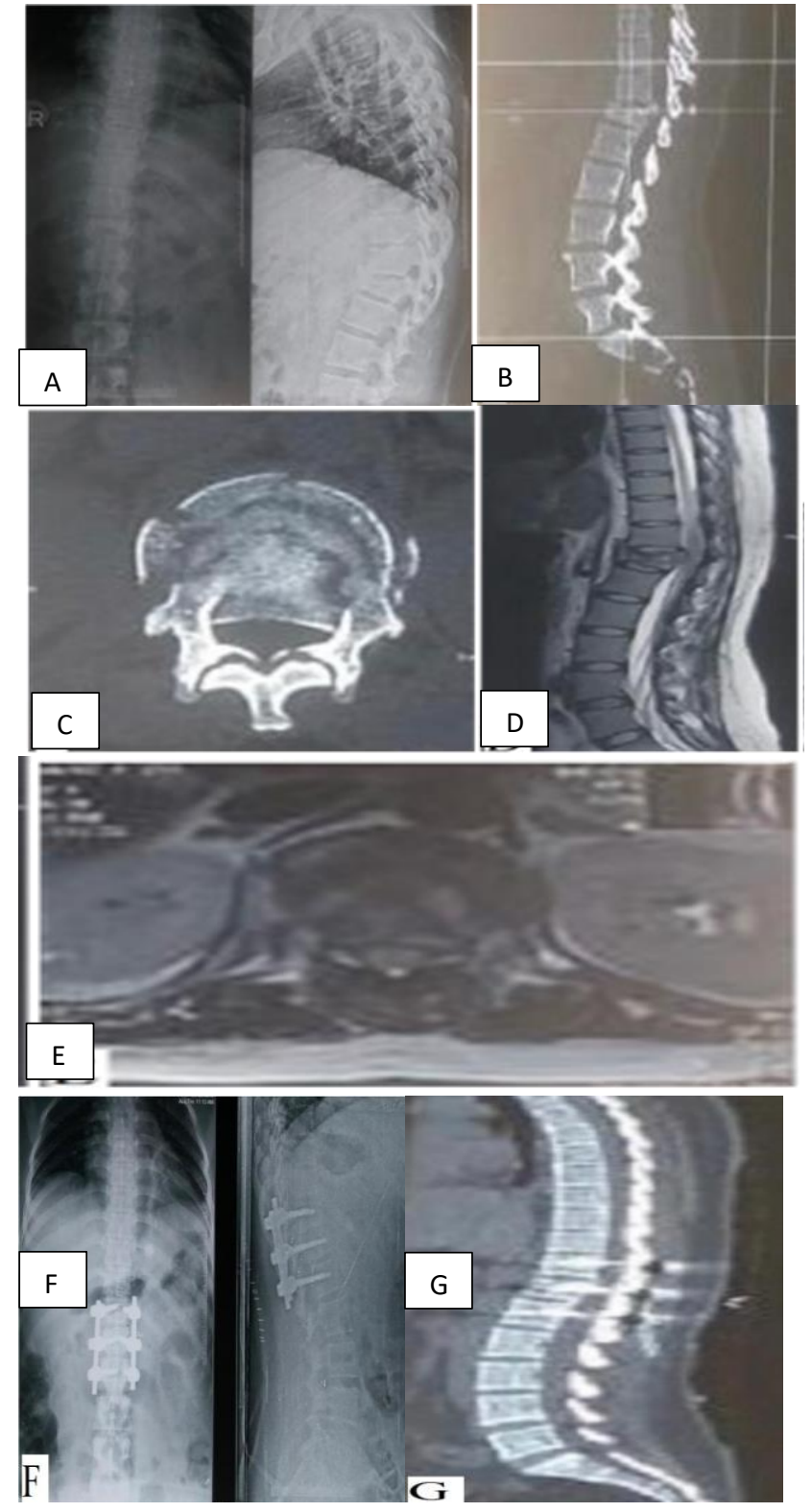

Figure 2: Films of 27-year-old male with D12 burst fracture caused by RTA and treated with OPSF. Preoperative- (A) Antero-posterior and lateral radiograph; (B and C) CT scan: sagittal and axial view; (D and E) MRI film: sagittal and axial view. Post-operative- (F) Antero-posterior and lateral radiograph; (G) CT scan: sagittal view.

Fractures were classified according to AO spine thoracolumbar spine injury classification system. ${ }^{14}$ All patients pre-operatively underwent complete clinicoradiological (X-ray, NCCT, MRI spine) examination. Neurological deficit was graded according to American spinal injury association (ASIA) impairment scale. ${ }^{15}$

\section{Operative techniques}

PPSF group: Following induction of general anesthesia, patient was placed on a radiolucent table in a prone position with silicon pads under the iliac crests and thorax.
The kyphosis of the fractured vertebral body was corrected by hyperextension. Fluoroscopic images were obtained in the anteroposterior and lateral planes to conform that the pedicles could be adequately visualized. Landmarks for pedicle access were drawn on the skin. Entry points were chosen for the pedicles that were to be fitted with instrumentation. An approximately $15 \mathrm{~mm}$ incision was made at the skin entry point and extended into the underlying subcutaneous tissue. A guide wire was used to perforate the fascia, and a series of sequential dilators were used to dilate the fascia and separate the underlying paraspinous muscles right down to the spine. The dilators were removed, and a pedicle pilot hole was made under Carm fluoroscopic guidance employing a tracked awl and a pedicle probe. A self-tapping, cannulated pedicle screw with an appropriate length and diameter was inserted into the vertebra through the guide wire under the protection of the outside catheter. All procedures were under C-arm fluoroscopic image guidance. Using the aforementioned steps, all other screws were put in sequentially and guide wire and protective catheter were removed. Two rods of appropriate lengths were inserted through the upper incision to reach the caudal pedicle screw, and rods were fixed using cranial bolt heads. The rods could also be lengthened to restore the height of the fractured vertebra, if necessary, and the cranial bolt heads were tightened subsequently. Bipolar forceps were used to control any wound hemorrhaging. The incisions were closed after irrigation, and no drainage was installed.

OPSF group: The same pre-operative procedure as utilized in the percutaneous approach was used for the OPSF group. The positions of the fractured vertebrae were determined and marked using the $\mathrm{C}$-arm. After routine sterilization and placement of the drapes, midline incision of required length was made at the surgical level and then separated the subcutaneous tissue and the longissimus and multifidus muscles to expose the space around the pedicle entry point. Required number of pedicle screws were implanted sequentially by free hand, and AP and lateral fluoroscopy images were taken to make sure that the screws were placed in their ideal positions. Two rods of appropriate lengths were implanted, and the height of the vertebral body was restored by lengthening the rods appropriately. The locations of the implants were again confirmed by $\mathrm{C}$-arm images. The incisions were irrigated and closed over drain placement.

Post-operatively patients were advised brace, subjected for physiotherapy and followed up of a minimum of one year. Both groups were compared in terms of patient demographics (age, gender), mechanism of injury (MOI), subjective pain perception, operation time, intraoperative blood loss, post-operative hospitalization time, complications, neurological and radiological (anterior vertebral body height, sagittal Cobb angle, vertebral body angle) improvement. The visual analog scores (VAS), anterior vertebral body height $(\mathrm{AVBH})$, vertebral body angle (VBA), and Cobb's angle (CA) were evaluated at 
pre-operation, the third day after surgery, and the final follow-up.

\section{Statistical analysis}

All data were entered into a Microsoft excel spreadsheet. Variables with continuous data were reported as the means and standard deviations. Independent sample t-tests were used to compare the outcomes between the two groups. These statistical tests were 2-tailed, and $\mathrm{p}<0.05$ was considered statistically significant. The statistical analyses were conducted using SPSS version 19 (SPSS Inc., Chicago, IL, USA).

\section{RESULTS}

\section{Baseline characteristics of patients}

The demographic and clinical characteristics of 30 patients, including $66.67 \%$ males and $33.33 \%$ females, were summarized in Table 1 . There were $73.33 \%$ males and $26.67 \%$ females in the OPSF group, and $60 \%$ males and $40 \%$ females in the PPSF group. The average age of patients in the OPSF group and the PPSF group was $39.53 \pm 16.93$ years (ranging from 18 to 67 years old) and $38.13 \pm 15.20$ years (ranging from 19 to 65 years old), respectively. RTA was the most common mode of injury occurred in $11(36.67 \%)$ patients followed by fall from height in $10(33.33 \%)$ patients. $46.66 \%$ of patients sustained injury at level of thoraco-lumbar junction (T12L1 level).

The variables including mean age (year), gender, level and mechanism of injury, between OPSF group and PPSF group weren't considered the significantly different (all $\mathrm{p}>0.05$ ). All of the patients were followed up with a mean time of 19.2 \pm 4.61 months (ranging from twelve to twentyeight months).

\section{Operation indexes}

In the PPSF group, the operation time, intraoperative bleeding and postoperative hospital stay duration were significantly less than those in the open pedicle screw fixation group (all p<0.05) (Table 2). The average operation duration was $115.26 \pm 14.59$ minutes $(93-140)$ in the OPSF group versus $101.40 \pm 12.88$ minutes (80-125) in the PPSF group. The average blood loss was $444.33 \pm 127.90 \mathrm{ml}(300-700)$ in OPSF group versus $196.33 \pm 70.11 \mathrm{ml}(110-340)$ in PPSF group. None of the patients PPSF group required a blood transfusion. However, there were 2 patients who needed a blood transfusion in the OPSF group. The average post-op stay for the OPSF group was $6.6 \pm 2.69$ days (3-12) and for PPSF group $4.4 \pm 1.76$ days (3-9).

Table 1: Demographic and clinical characteristics of patients.

\begin{tabular}{|lllll|}
\hline Variables & Total & OPSF group & PPSF group & P value \\
\hline No. of patients & 30 & 15 & 15 & \\
\hline Mean age (year) & $38.83 \pm 15.83$ & $39.53 \pm 16.93$ & $38.13 \pm 15.20$ & 0.813 \\
\hline Gender (\%) & & & & \\
\hline Male & $20(66.67)$ & $11(73.33)$ & $9(60)$ & 0.071 \\
\hline Female & $10(33.33)$ & $4(23.67)$ & $6(40)$ & \\
\hline Mechanism of injury $(\%)$ & & & $5(33.33)$ \\
\hline RTA & $11(36.67)$ & $6(40)$ & $6(40)$ \\
\hline Fall from height & $10(33.33)$ & $4(26.67)$ & $3(20)$ \\
\hline Sports & $6(20)$ & $3(20)$ & $1(6.67)$ \\
\hline Others & $3(10)$ & $2(13.33)$ & \\
\hline Level of injury $(\%)$ & & & $1(6.67)$ \\
\hline T10 & $2(6.67)$ & $1(6.67)$ & $2(13.33)$ \\
\hline T11 & $4(13.33)$ & $2(13.33)$ & $3(26.67)$ \\
\hline T12 & $7(23.33)$ & $3(20)$ & $3(20)$ \\
\hline L1 & $7(23.33)$ & $4(26.67)$ & $2(13.33)$ \\
\hline L2 & $4(13.33)$ & $2(13.33)$ & $1(6.67)$ \\
\hline L3 & $3(10)$ & $2(13.33)$ & $2(13.33)$ \\
\hline L4 & $3(10)$ & $1(6.67)$ & 0 \\
\hline L5 & 0 & 0 & \\
\hline
\end{tabular}

\section{Radiologic parameters}

Statistical analysis of data (Table 3) showed no significant difference in the sagittal cobb's angle (CA), fracture vertebral body angle (VBA), anterior vertebral body height
$(\mathrm{AVBH})$ on pre-operative, immediate post-operative and final follow up of 12 months between the two surgical techniques (all $\mathrm{p}>0.05$ ). In OPSF group, the average preop sagittal Cobb's angle was $23.06 \pm 4.58$, the immediate post-op $8.86 \pm 2.87$ and at final follow-up was $13.20 \pm 2.85$. The average correction was $9.86 \pm 4$.64. In PPSF group, the 
average pre-op CA was $22.06 \pm 4.74$, the immediate postop 8.66 \pm 2.46 and at final follow-up was $13.73 \pm 2.40$. The average correction was $8.33 \pm 4.11$. OPSF group had better correction than PPSF group but difference was not significant $(\mathrm{p}=0.346)$.

Table 2: Operation indexes in two groups.

\begin{tabular}{|llll|}
\hline $\begin{array}{l}\text { Operation } \\
\text { indexes }\end{array}$ & $\begin{array}{l}\text { OPSF } \\
\text { group }\end{array}$ & $\begin{array}{l}\text { PPSF } \\
\text { group }\end{array}$ & P \\
\hline $\begin{array}{l}\text { Operation time } \\
\text { (min) }\end{array}$ & $\begin{array}{l}115.26 \pm \\
14.59\end{array}$ & $\begin{array}{l}101.4 \pm \\
12.88\end{array}$ & 0.01 \\
\hline $\begin{array}{l}\text { Surgical blood } \\
\text { loss (ml) }\end{array}$ & $\begin{array}{l}444.33 \pm \\
127.90\end{array}$ & $\begin{array}{l}190.66 \pm \\
74.39\end{array}$ & 0.001 \\
$\begin{array}{l}\text { Post op } \\
\text { hospital stay } \\
\text { (days) }\end{array}$ & $6.6 \pm 2.69$ & $4.4 \pm 1.76$ & 0.013 \\
\hline
\end{tabular}

Table 3: Radiological parameters in two groups.

\begin{tabular}{|c|c|c|c|}
\hline $\begin{array}{l}\text { Radiological } \\
\text { parameters }\end{array}$ & $\begin{array}{l}\text { OPSF } \\
\text { group }\end{array}$ & $\begin{array}{l}\text { PPSF } \\
\text { group }\end{array}$ & $\mathbf{P}$ \\
\hline \multicolumn{4}{|c|}{ Sagittal Cobb's angle $\left(^{0}\right)$} \\
\hline Pre-operative & $23.06 \pm 4.58$ & $22.06 \pm 4.74$ & 0.562 \\
\hline 3-day post op & $8.86 \pm 2.87$ & $8.66 \pm 2.46$ & 0.839 \\
\hline 12-month post op & $13.20 \pm 2.85$ & $13.73 \pm 2.40$ & 0.584 \\
\hline \multicolumn{4}{|c|}{ Vertebral body angle $\left({ }^{0}\right)$} \\
\hline Pre-operative & $17.33 \pm 4.35$ & $16.8 \pm 4.42$ & 0.741 \\
\hline 3-day post op & $8.1 \pm 3.54$ & $8.66 \pm 3.19$ & 0.668 \\
\hline 12 -month post op & $10.2 \pm 3.05$ & $10.33 \pm 2.94$ & 0.903 \\
\hline \multicolumn{4}{|c|}{ Anterior vertebral body height $\left(^{0}\right)$} \\
\hline Pre-operative & $59.93 \pm 8.89$ & $61.66 \pm 8.82$ & 0.596 \\
\hline 3-day post op & $91.46 \pm 5.46$ & $90.06 \pm 5.06$ & 0.472 \\
\hline 12-month post op & $88.13 \pm 5.59$ & $87.73 \pm 4.77$ & 0.834 \\
\hline
\end{tabular}

In OPSF group, the average pre-op VBA was $17.33 \pm 4.35$, the immediate post-op $8.1 \pm 3.54$ and at final follow-up was 10.2 \pm 3.05 . Correction of $7.13 \pm 1.99$ was achieved. In PPSF group, the average pre-op VBA was $16.8 \pm 4.42$, the immediate post-op $8.66 \pm 3.19$ and at final follow-up was $10.33 \pm 2.94$. The average correction was $6.46 \pm 2.09$. OPSF group had better correction than PPSF group but difference was not significant $(\mathrm{p}=0.380)$.
In OPSF group, average anterior vertebral body height (percentage of normal) was $59.93 \pm 8.89 \%$ before surgery and $88.13 \pm 5.59 \%$ at final follows up, yielding an average vertebral body height restoration of $28.20 \pm 8.49 \%$, but

$61.66 \pm 8.82 \%, 87.73 \pm 4.77 \%$ and $26.06 \pm 9.26 \%$ resp in the PPSF group. Average AVBH restoration was more in OPSF group but difference was not significant ( $\mathrm{p}=0.516)$.

\section{Effectiveness parameter}

Before operation, VAS scores for back pain were $7.86 \pm 1.30$ and $7.66 \pm 1.56$ points in the OPSF group and PPSF group, respectively, and these were remarkably decreased in both groups after surgery (Table 4). However, there was no significant difference of VAS scores at the 12 months follow-up between two groups $(p=0.808)$.

Table 4: Visual analog score in two groups.

\begin{tabular}{|llll|}
\hline VAS & $\begin{array}{l}\text { OPSF } \\
\text { group }\end{array}$ & $\begin{array}{l}\text { PPSF } \\
\text { group }\end{array}$ & P \\
\hline Pre-op & $7.86 \pm 1.30$ & $7.66 \pm 1.54$ & 0.7 \\
\hline 3-day post op & $3.8 \pm 0.94$ & $3.53 \pm 0.99$ & 0.45 \\
\hline $\begin{array}{l}\text { 12-months } \\
\text { post op }\end{array}$ & $2.13 \pm 0.99$ & $2.06 \pm 0.79$ & 0.84 \\
\hline
\end{tabular}

As shown in Table 5, there was no statistical significance in preoperative neurological status (ASIA grading system) between OPSF group and PPSF $(\mathrm{p}=1)$. On final follow-up, $1(6.67 \%)$ patient with grade A improved to grade B, 1 (6.67\%) patient from grade B improved to grade D, 4 (26.67\%) out of 7 patients improved from grade $C$ to grade E and $4(26.67 \%)$ out of 5 patients improved from grade D to grade $\mathrm{E}$ in OPSF group. Whereas, $1(6.67 \%)$ patient with grade A improved to grade B, $1(6.67 \%)$ patient from grade B improved to grade D, 3 (20\%) out of 5 patients improved from grade $\mathrm{C}$ to grade $\mathrm{E}$ and all $6(40 \%)$ patients improved from grade D to grade $\mathrm{E}$ in PPSF group. No patient in either group with grade $\mathrm{E}$ pre-op had any change in neurological status.

Table 5: Change in neurological status (ASIA grading system) in two groups.

\begin{tabular}{|c|c|c|c|c|c|c|}
\hline \multirow{2}{*}{ Surgical technique } & \multirow{2}{*}{$\begin{array}{l}\text { Pre-op status ( } \% \text { ) } \\
\text { ASIA grading }\end{array}$} & \multicolumn{5}{|c|}{ On final follow-up (\%) } \\
\hline & & A & B & $\mathbf{C}$ & D & $\mathbf{E}$ \\
\hline \multirow{5}{*}{ OPSF group } & Grade A-1 (6.67) & & & & & \\
\hline & Grade B- 2 (13.33) & & & $1(6.67)$ & $1(6.67)$ & \\
\hline & Grade C-7 (46.67) & & & & $3(20)$ & $4(26.67)$ \\
\hline & Grade D-5 (33.33) & & & & $1(6.67)$ & $4(26.67)$ \\
\hline & Grade E-0 & & & & & \\
\hline \multirow{5}{*}{ PPSF group } & Grade A-1 (6.67) & & & & & \\
\hline & Grade B-3 (20) & & & $2(13.33)$ & $1(6.67)$ & \\
\hline & Grade C-5 (33.33) & & & & $2(13.33)$ & $3(20)$ \\
\hline & Grade D-6 (40) & & & & & $6(40)$ \\
\hline & Grade E-0 & & & & & \\
\hline
\end{tabular}




\section{Postoperative complications}

There was no significant difference in postoperative complications between PPSF group and OPSF group (p>0.620) (Table 6). Two patients $(13.33 \%)$ in OPSF group and 1 (6.67\%) in PPSF group had developed superficial infection in early post op period. All these were treated with higher antibiotics \& regular dressing. None of the patients had deep infection. One patient $(6.67 \%)$ had developed hardware failure (implant loosening and rod migration) after a period of 9 months in PPSF group, which was treated by implant removal and brace was advised. One $(6.67 \%)$ patient in each group had developed worsening of urinary tract infection (UTI) which was managed by intermittent catheterization, bladder wash and antibiotics. Two patients $(13.33 \%)$ in OPSF group and 1 $(6.67 \%)$ in PPSF group had developed stage II pressure ulcer over sacrum during follow up period. All these were managed by non-operative wound care. None of the patient in either group had complications of neurological deterioration, chest infection or DVT.

Table 6: Postoperative complications in two groups.

\begin{tabular}{|c|c|c|c|}
\hline Complication & OPSF & PPSF & $\mathbf{P}$ \\
\hline Infection & 2 & 1 & \multirow{4}{*}{0.62} \\
\hline Hardware failure & 0 & 1 & \\
\hline Pressure ulcer & 2 & 1 & \\
\hline UTI & 1 & 1 & \\
\hline
\end{tabular}

\section{DISCUSSION}

Burst fractures of the spine account for $14 \%$ of all spinal injuries. ${ }^{16}$ There has been substantial controversy regarding the operative management of such fractures. OPSF, more commonly utilized in clinical practices, has a clearer operative field and exposure to the vertebrae, it is associated with a large amount of blood loss and slow postoperative recovery. On the other side, PPSF could reduce the damage of paraspinal soft tissue and promote the recovery of scaffold structure of vertebral trabecular bone. ${ }^{17}$ In this study, we evaluated the effectiveness between OPSF and PPSF for treating thoracolumbar burst fractures with spinal injuries.

A total of 30 patients with thoracolumbar burst fracture with spinal injuries were divided into OPSF and PPSF group with 15 patients in each group. The demographic and clinical variables (Table 1) including age, gender, fracture level, mechanism of injury and ASIA grade in both the groups weren't significantly different. Type of neurological deficit (complete or incomplete) does influence the choice of surgical approach. Some surgeons are of the opinion that the efficacy of indirect decompression was greater particularly if operated within 72 hours of trauma. ${ }^{3,18}$ Taking this into consideration, in present study we did indirect decompression of fracture vertebra, by distracting posterior pedicle-screw construct in both groups. In PPSF group, operation time, intraoperative blood loss and postoperative hospital stay were significantly lower than those in the OPSF group (Table 2), which is similar to previous research. ${ }^{[19]} \mathrm{A}$ new meta-analysis also confirmed our study results. ${ }^{20}$

For comparison of postoperative recovery of the two groups, preoperative and postoperative imaging findings were analyzed. CA, VBA and AVBH were the radiographic parameters of the normal anatomical position. ${ }^{21}$ In both the groups, CA and VBA were significantly decreased, whereas AVBH increased after surgery (Table 3). Despite that, they weren't significantly different. This suggested that there was no significant difference in the recovery of thoracolumbar fracture and no greater change in the thoracolumbar anatomical structure, which was beneficial to its function restoration. These finding were similar to those of Wang et al. ${ }^{19}$ However, Patil et al found significant correction of sagittal Cobb's angle in OPSF group on final follow-up. ${ }^{3}$ Fan et al found significant differences in the pre-operative and postoperative vertebral body angle and Cobb's angle, which were significantly better in the mini-open Wiltse approach with pedicle screw fixation (MWPSF) group than percutaneous pedicle screw fixation (PPSF). ${ }^{22}$

VAS score and neurological status are also indicators of the effect of surgery. After surgery, VAS score was remarkably decreased in both groups but difference wasn't significant between two groups (Table 4). Wang et al. ${ }^{19}$ and Li $\mathrm{K}$ et al found significant difference of VAS score after surgery between 2 groups. ${ }^{23}$ Decreased postoperative pain may lead to earlier mobilization, shorter recovery time, shortened hospital stay, and reduced hospital costs.

As shown in Table 5, there was no statistical significance in preoperative neurological status (ASIA grading system) between OPSF group and PPSF. However, there was rapid neurological improvement in both groups which could be achieved by means of distraction of fracture segment during surgery. The efficacy of indirect decompression could be greater as the surgery was performed within 5 days of trauma which corresponded with other study. ${ }^{18}$ Also, early mobilization in PPSF group due to reduce postoperatively pain and early initiation of aggressive and proper physiotherapy have contributed for better neurological outcome.

Common postoperative complications in both studies were superficial infections, pressure ulcer and UTI worsening (Table 6). Hardware failure was seen only in one case of PPSF group. However, there was no significant difference in postoperative complications between two groups $(p>0.620)$. None of the patient in either group had complications of neurological deterioration, chest infection or DVT. Wang et al also found statically insignificant difference in postoperative complications between two groups while such complications were more common in open pedicle screw fixation with indirect decompression (OPSFD) in Patil et al study. ${ }^{3,19}$ 
Limitations of this study include (a) sample size was small with short term follow up, (b) blood loss in postoperative period in drain weren't considered, and (c) incision length in two groups weren't compared. So, there is a need for further long term, randomized and multicentric trials to verify our findings.

\section{CONCLUSION}

Patients with thoracolumbar burst fractures can be effectively managed with PPSF or OPSF. PPSF were superior in terms of blood loss, operating time and hospitalization stay, but there seems to no significant effect on radiologic outcomes and postoperative complications using percutaneous procedures compared open procedures.

\section{Funding: No funding sources}

Conflict of interest: None declared

Ethical approval: The study was approved by the institutional ethics committee

\section{REFERENCES}

1. Samelson EJ, Hannan MT, Zhang Y, Genant HK, Felson DT, Kiel DP. Incidence and risk factors for vertebral fracture in women and men: 25 -year followup results from the population-based Framingham study. J Bone Miner Res 2006;21:1207-14.

2. Leucht $\mathrm{P}$, Fischer $\mathrm{K}$, Muhr G, Mueller EJ. Epidemiology of traumatic spine fractures. Injury 2009;40:166-72.

3. Patil RP, Joshi V, Pamecha C, Kumar P, Bisnoi UP, Singh O. Comparative Study Between Short Segment Open Versus Percutaneous Pedicle Screw Fixation with Indirect Decompression in Management of Acute Burst Fracture of Thoracolumbar and Lumbar Spine with Minimal Neurological Deficit in Adults. J Spine. 2016;5:339.

4. Tian F, Tu LY, Gu WF, Zhang EF, Wang ZB, Chu G, et al. Percutaneous versus open pedicle screw instrumentation in treatment of thoracic and lumbar spine fractures. A systematic review and metaanalysis. Medicine. 2018;97:1-12.

5. Ajay MB, Vijayakumar AV. Comparative study between conventional open spine pedicle screw fixation surgery and minimally invasive percutaneous pedicle screw fixation in the management of thoracolumbar spine fracture in adult. Int J Ortho Sci. 2016;2:154-9.

6. Wang MY. Percutaneous thoracolumbar pedicle screw fixation: is it time to revisit spinal fracture treatment? World Neurosurg. 2010;74:570-1.

7. Fennell VS, Palejwala S, Skoch J, Stidd DA, Baaj AA. Freehand thoracic pedicle screw technique using a uniform entry point and sagittal trajectory for all levels: preliminary clinical experience. J Neurosurg Spine. 2014;21:778-84.

8. Alvine GF, Swain JM, Asher MA, Burton DC. Treatment of thoracolumbar burst fractures with variable screw placement or Isola instrumentation and arthrodesis: case series and literature review. J Spinal Disord Tech. 2004;17:251-64.

9. Kim DY, Lee SH, Chung SK, Lee HY. Comparison of multifidus muscle atrophy and trunk extension muscle strength: percutaneous versus open pedicle screw fixation. Spine. 2005;30:123-9.

10. Rampersaud YR, Annand N, Dekutoski MB. Use of minimally invasive surgical techniques in the management of thoracolumbar trauma: current concepts. Spine 2006;31:S96-102.

11. Smith JS, Ogden AT, Fessler RG. Minimally invasive posterior thoracic fusion. Neurosurg Focus. 2008;25:E9.

12. Youkilis AS, Quint DJ, McGillicuddy JE, Papadopoulos SM. Stereotactic navigation for placement of pedicle screws in the thoracic spine. Neurosurgery. 2001;48:771-8.

13. Lee JY, Vaccaro AR, Lim MR, Öner FC, Hulbert RJ, Hedlund $\mathrm{R}$ et al. Thoracolumbar injury classification and severity score: a new paradigm for the treatment of thoracolumbar spine trauma. J Orthop Sci. 2005;10:671-5.

14. Vaccaro AR, Oner C, Kepler CK, Dvorak M, Schnake $\mathrm{K}$, Bellabarba $\mathrm{C}$ et al. AOSpine thoracolumbar spine injury classification system. Fracture description, neurological status, and key modifiers. Spine. 2013;38:2028-37.

15. Roberts TT, Leonard GR, Cepela DJ. Classifications in Brief: American Spinal Injury Association (ASIA) Impairment Scale. Clin Orthop Relat Res. 2017;475:1499-1504.

16. Heary RF, Kumar S. Decision-making in burst fractures of the thoracolumbar and lumbar spine. Indian J Orthop. 2007;41:268-76.

17. Wood KB, Li W, Lebl DR, Ploumis A. Management of thoracolumbar spine fractures. Spine J. 2014;14:145-64.

18. Cimatti M, Forcato S, Polli F, Miscusi M, Frati A, Raco A. Pure percutaneous pedicle screw fixation without arthrodesis of 32 thoraco-lumbar fractures: clinical and radiological outcome with 36-month follow-up. Eur Spine J. 2013;22:925-32.

19. Wang B, Fan Y, Dong J, Wang H, Wang F, Liu Z et al. A retrospective study comparing percutaneous and open pedicle screw fixation for thoracolumbar fractures with spinal injuries. Medicine (Baltimore) 2017;96:e8104.

20. Phan K, Rao PJ, Mobbs RJ. Percutaneous versus open pedicle screw fixation for treatment of thoracolumbar fractures: systematic review and meta-analysis of comparative studies. Clin Neurol Neurosurg. 2015;135:85-92.

21. Wang J, Zhou Y, Zhang ZF, Li CQ, Zheng WJ, Liu J. Radiological study on disc degeneration of thoracolumbar burst fractures treated by percutaneous pedicle screw fixation. Eur Spine J. 2013;22:489-94.

22. Fan Y, Zhang J, He X, Hang Y, Wu Q, Hao D. A Comparison of the Mini-Open Wiltse Approach with Pedicle Screw Fixation and the Percutaneous Pedicle 
Screw Fixation for Neurologically Intact Thoracolumbar Fractures. Med Sci Monit. 2017;23:5515-21.

23. Li K, Li Z, Ren X, Xu H, Zhang W, Luo D et al. Effect of the percutaneous pedicle screw fixation at the fractured vertebra on the treatment of thoracolumbar fractures. Int Orthop. 2016;40:1103-10.
Cite this article as: Kumar R, Sarkar B, Ifthekar S, Mittal S, Kandwal P, Azam Q. Analysis of outcome of percutaneous versus open pedicle screw fixation in the treatment of thoraco-lumbar spine fractures: a prospective comparative study. Int J Res Orthop 2021:7:343-50. 